\title{
PRIMEIRO REGISTRO DE Diaphorina citri KUWAYAMA, 1908 (HEMIPTERA: LIVIIDAE) PARA O ESTADO DE RORAIMA, BRASIL
}

\author{
Alberto Luiz Marsaro Júnior ${ }^{1}$, Aline Sartori Guidolin ${ }^{2}$, Fernando Luís Cônsoli ${ }^{2}$, Juliana Freitas- \\ Astúa $^{3}$ \\ ${ }^{1}$ Laboratório de Entomologia, Embrapa Trigo, Passo Fundo - RS, E-mail: alberto.marsaro@embrapa.br \\ ${ }^{2}$ Departamento de Entomologia e Acarologia, ESALQ/USP, E-mail: alinesguidolin@gmail.com, fconsoli@usp.br \\ ${ }^{3}$ Embrapa Mandioca e Fruticultura e Centro APTA Citros Sylvio Moreira-IAC, E-mail: juliana.astua@embrapa.br
}

\section{RESUMO}

Este é o primeiro registro da espécie Diaphorina citri Kuwayama (Hemiptera: Liviidae) para o estado de Roraima, Brasil. Exemplares deste inseto foram coletados no município de Boa Vista sobre plantas de Citrus limon (L.) e Murraya paniculata (L.) Jack. (Rutaceae). Observou-se a predação de ninfas de D. citri por larvas de Ceraeochrysa fairchildi Banks (Neuroptera: Chrysopidae).

Palavras-chave: Amazônia, Citrus limon, distribuição geográfica, inimigos naturais, Murraya paniculata

\section{FIRST RECORD OF Diaphorina citri KUWAYAMA, 1908 (HEMIPTERA: LIVIIDAE) FOR THE STATE OF RORAIMA, BRAZIL}

\section{ABSTRACT}

This is the first report on the occurrence of Diaphorina citri Kuwayama (Hemiptera: Liviidae) in the state of Roraima, Brazil. Specimens of this insect were collected in Boa Vista on plants of Citrus limon (L.) and Murraya paniculata (L.) Jack. (Rutaceae). We also report the predation of $D$. citri nymphs by larvae of Ceraeochrysa fairchildi Banks (Neuroptera: Chrysopidae).

Keywords: Amazon, Citrus limon, geographical distribution, natural enemies, Murraya paniculata

Diaphorina citri Kuwayama, 1908 (Hemiptera: Liviidae) é vetor da mais importante doença dos citros, o huanglongbing (HLB) ou greening, que tem reduzido a produção na cultura em vários países do mundo, inclusive no Brasil. De acordo com levantamentos do Fundo de Defesa da Citricultura a doença se disseminou rapidamente em São Paulo desde o seu $1^{\circ}$ relato, em 2004, passando de 3,4\% 
para $64,1 \%$ dos talhões de laranjeiras com pelo menos uma planta infectada, em 2012. A incidência de plantas sintomáticas também aumentou significativamente, passando de 0,58\%, em 2008, para 6,91\%, em 2012 (FUNDECITRUS, 2014).

Plantas do gênero Citrus e também outras rutáceas, como a ornamental murta [Murraya paniculata (L.) Jack.], hospedam não apenas as bactérias causadoras do HLB, "Candidatus Liberibacter americanus" e "Candidatus Liberibacter asiaticus", mas também o psilídeo dos citros, D. citri, com implicações na epidemiologia da doença (LOPES et al., 2010).

Os principais inimigos naturais citados para D. citri pertencem às ordens Coleoptera, família Coccinellidae, Olla $V$ nigrum (Mulsant, 1866), Chilocorus cacti (Linnaeus, 1767), Cycloneda sanguinea (Linnaeus, 1763), Nephus sp. e Pentilia sp.; Neuroptera, família Chrysopidae, Ceraeochrysa sp. (RODRÍGUEZPALOMERA et al., 2012); e Hymenoptera, familia Eulophidae, Tamarixia radiata (Waterston, 1922) (PARRA et al., 2010; GÓMEZ-TORRES et al., 2012; RODRÍGUEZ-PALOMERA et al., 2012).

No Brasil, a primeira citação de ocorrência de $D$. citri é datada da década de 30, para o estado do Rio de Janeiro (COSTA
LIMA, 1936). Na década de 60 esse psilídeo já havia sido registrado para os estados Amazonas, Bahia, Ceará, Pará, Pernambuco e São Paulo (D’ARAUJO E SILVA et al., 1968).

Visto que são escassos os estudos sobre a distribuição de $D$. citri na região Norte do Brasil e que não há relatos oficiais da ocorrência desta praga e de seus inimigos naturais no Estado de Roraima foi realizado um levantamento no município de Boa Vista, no período de fevereiro a junho de 2010, visando a detecção dessa praga e de seus inimigos naturais.

As amostragens foram realizadas em pequenas propriedades rurais e também na área urbana de Boa Vista que apresentavam hospedeiros de D. citri. Exemplares de psilídeos foram coletados em plantas de limão galeguinho, Citrus limon (L.), $\mathrm{N} 02^{\circ}$ 45' 53.0" e W 60 44' 27.2"; e murta, $M$. paniculata, N $02^{\circ} 49^{\prime} 44.5^{\prime \prime}$ e W 60 40' 18.0”; e enviados para identificação taxonômica para a ESALQ/USP, em Piracicaba/SP. Larvas de crisopídeos, observadas predando esses psilídeos, foram coletadas e alimentadas até o estágio adulto para posterior identificação taxonômica na UNESP, em Jaboticabal/SP. Os adultos dos psilídeos foram preservados em álcool para posterior extração do DNA genômico, 
visando à condução de análises moleculares, utilizando-se o gene da COI como marcador molecular.

As análises parciais do gene da COI confirmaram a identificação dos psilídeos coletados como D. citri, sendo os crisopídeos, após análises morfológicas, identificados como Ceraeochrysa fairchildi (Banks, 1946). Esse é o primeiro registro de D. citri e de sua predação por C. fairchildi em Roraima, o terceiro estado da região norte e da Amazônia com ocorrência desta praga, que está ampliando sua distribuição no Brasil.

Estudos futuros devem ser realizados em pomares comerciais de citros, em todo o estado de Roraima, a fim de verificar a provável ocorrência de D. citri, se há insetos infectivos com as bactérias causadoras do greening, se existem plantas contaminadas por essa doença e se há inimigos naturais eficientes que possam fazer parte de um programa de controle biológico dessa praga. Esses estudos poderão subsidiar futuros programas de manejo integrado de $D$. citri para o estado de Roraima.

\section{AGRADECIMENTOS}

Ao Dr. Sergio de Freitas $^{\dagger}$ (Unesp/Jaboticabal) pela identificação da espécie Ceraeochrysa fairchildi (Banks, 1946).

\section{REFERÊNCIAS BIBLIOGRÁFICAS}

COSTA LIMA, A. 1936. Terceiro catálogo de insetos que vivem nas plantas do Brasil. Rio de Janeiro: Directoria da Estatística da Producção, 460p.

D'ARAUJO E SILVA, A.G.; GONÇALVES, C. R.; GALVÃO, D. M.; GONÇALVES, A.J.L.; GOMES, J.; SILVA,M.N.; SIMONI, L. 1968. Quarto catálogo dos insetos que vivem nas plantas do Brasil, seus parasitos e predadores. Rio de Janeiro: Ministério da Agricultura, 906p.

FUNDECITRUS. 2014. Levantamentos: greening. Disponível em: $<$ http://www.fundecitrus.com.br/levanta mentos/greening/10>. Acesso em: $24 \backslash 03 \backslash 2014$.

GÓMEZ-TORRES, M.L.; NAVA, D.E.; PARRA, J.R.P. 2012. Life table of Tamarixia radiate (Hymenoptera: Eulophidae) on Diaphorina citri (Hemiptera: Psyllidae) at different temperatures. Journal of Economic Entomology, College Park, v.105, n.2, p.338-343.

LOPES, S.A.; FRARE, G.F.; CAMARGO, L.E.A.; WULFF, N.A.; TEIXEIRA, D.C.; BASSANEZI, R.B.; BEATTIE, G.A. C.; AYRES, A.J. 2010. Liberibacters associated with orange jasmine in Brazil: incidence in urban areas and relatedness to citrus liberibacters. Plant Pathology, London, v.59, p.1044-1053.

PARRA, J.R.P.; LOPES, J.R.S.; GÓMEZTORRES, M.L.; NAVA, D.E.; PAIVA, P.E.B. 2010. Bioecologia do vetor Diaphorina citri e transmissão de bactérias associadas ao huanglongbing. Citrus Research \& Technology, Cordeirópolis, v.31, n.1, p.37-51.

RODRÍGUEZ-PALOMERA, M.; CAMBERO-CAMPOS, J.; ROBLESBERMÚDEZ, A.; CARVAJALCAZOLA, C.; ESTRADA-VIRGEN, O. 
2012. Natural enemies associated to Diaphorina citri Kuwayama (Hemiptera: Psyllidae) in Citrus latifolia Tanaka, in the state of Nayarit, Mexico. Acta Zoológica Mexicana, México, v.28, n.3, p.625-629.

Recebido em: 09\04\2014 Aceito para publicação em:29\11 2014 